\title{
CONTROL OF HEMIPTERAN PESTS IN LUCERNE AND RED CLOVER SEED CROPS USING LAMBDA-CYHALOTHRIN
}

\author{
N.C. SCHROEDER \\ AgResearch, P.O. Box 60, Lincoln
}

\begin{abstract}
The most abundant hemipteran pests found in a lucerne and red clover crop were Australian crop mirid (ACM, Sidnia kinbergi Stål) and sowthistle aphid (Hyperomyzus lactucae (L.), respectively. Lambdacyhalothrin applied at $10 \mathrm{~g} / \mathrm{ha}$ significantly reduced numbers of both species. In lucerne ACM numbers remained significantly low in the treated plots up to 34 DAT, while in red clover ACM numbers were significantly lower up to 16 DAT. Pacific damsel bug (Nabis kinbergii (Reuter)) and harvestman (Phalangium opilio L.) were the most abundant natural enemies collected in both crops. There were no significant differences in numbers of both species or seed yields between the control and lambda-cyhalothrin treated plots.
\end{abstract}

Keywords: lambda-cyhalothrin, Sidnia kinbergi, lucerne, red clover, natural enemies.

\section{INTRODUCTION}

The common hemipteran pests found in forage legume seed crops are bluegreen lucerne aphid (Acyrthosiphon kondoi Shinji), potato mirid (Calocoris norvegicus Gmelin), brown shield bug (Dictyotus caenosus Westwood), Australian crop mirid (ACM, Sidnia kinbergi Stăl), and wheat bug (Nysius huttoni White) (Schroeder and Clifford 1995; Wightman and MacFarlane 1981). Schroeder and Clifford (1995) found that these pests occurred in large numbers at different times during the season in white clover seed crops grown in Canterbury. High potato mirid and bluegreen lucerne aphid numbers coincided with white clover (Trifolium repens $\mathrm{L}$.) inflorescence development and were, therefore, likely to be the key hemipteran pests in that crop. High numbers of brown shield bugs, ACM, and wheat bugs all occurred later in the season when later flowering forage legume crops like lucerne and red clover were likely to be adversely affected by their feeding injury (Schroeder and Clifford 1995).

ACM is regarded as the major hemipteran pest of lucerne seed crops (Donovan 1981; MacFarlane et al. 1981). High numbers of ACM (>5/10 sweeps of a sweep net) have also been observed in a red clover seed crop during the 1997 season (Schroeder unpublished). When the pyrethroid insecticide lambda-cyhalothrin was applied at 10 g/ha, ACM numbers decreased rapidly. Lambda-cyhalothrin has also been effective in controlling potato mirid and bluegreen lucerne aphid in white clover seed crops (Schroeder et al. 1996) and no lethal or sublethal effects on foraging honeybees have been observed (Gough and Wilkinson 1984). Currently, however, there are no chemicals registered for use against ACM in any forage legume seed crop.

Of the natural enemies commonly found in white clover crops, only populations of ladybird adults (mainly Coccinella undecimpunctata $\mathrm{L}$.) were significantly $(\mathrm{P}<0.05)$ reduced in the lambda-cyhalothrin treated plots (Schroeder et al. 1996). There was little effect on adult Tasmanian lacewing (Micromus tasmaniae Walker) and harvestman (Phalangium opilio L.) numbers.

Experiments were conducted to determine the effect of lambda-cyhalothrin application on common hemipteran pests, their natural enemies and resultant seed yields in a lucerne and red clover seed crop grown in Canterbury. 


\section{MATERIAL AND METHODS}

The lucerne experiment was conducted in a 5 ha, fifth year, Grasslands Otaio seed crop grown on a variable Templeton silt loam at Irwell. The red clover experiment was conducted in a 3.5 ha second year, Grasslands Hamua seed crop grown on a Tai Tapu silt loam at Tai Tapu.

The experimental design for both crops consisted of two treatments (control and treated) which were randomly allocated to paired plots. Each plot measured $10 \times 6 \mathrm{~m}$ and was selected on the basis of high and uniform plant growth within the paired-plot area $(20 \times 6 \mathrm{~m})$. There were four paired-plot replicates per crop.

The treated plots received an application of lambda-cyhalothrin (Karate, $50 \mathrm{~g} /$ litre EC) at $10 \mathrm{~g}$ in 400 litres of water/ha, while the control plots were sprayed with the equivalent of 400 litres/ha water only. Treatments were applied on 2 February 1998 by knapsack sprayer at $200 \mathrm{kPa}$ with a three metre spray boom fitted with XR Teejet 11002 VB nozzles set $500 \mathrm{~mm}$ apart.

Arthropod samples were collected with a $40 \mathrm{~cm}$ diameter sweep net. Ten $180^{\circ}$ sweeps, while walking through the crop, were taken per plot two days prior to spray application and at 2, 5, 9, 16, and 34 days after treatment (DAT) for the lucerne experiment and 2,5,13,15, and 34 DAT for the red clover experiment. Sweep net samples were consistently taken around mid-day on sunny days when insects were active. The red clover and lucerne crops were sprayed with the desiccant herbicide diquat (Reglone) on 4 and 18 April, respectively. Red clover $\left(6.3 \mathrm{~m}^{2}\right)$ and lucerne (5.6 $\mathrm{m}^{2}$ ) yield samples were cut from each plot, collected into wool packs, and dried in a glasshouse for four weeks. Herbage samples were then thrashed and cleaned by a screen-air draft seed separator and the seed weight recorded.

Arthropod data collected from the plots at each sampling date were analysed by a general analysis of variance model using the Poisson error distribution and seed weights were analysed by general analysis of variance, using Genstat for Windows.

\section{Lucerne}

\section{RESULTS}

Of the hemipteran pests collected in the control plots, potato mirid adults, aphids and wheat bug adults reached numbers $>1 / 10$ sweeps during the experiment, but only ACM nymphs and adults consistently recorded $>1 / 10$ sweeps for all sampling dates (Figures $1 \mathrm{a}$ and $\mathrm{b})$. The mean number $( \pm \mathrm{SE})$ of potato mirid adults in the control plots decreased from $3.8( \pm 1) / 10$ sweeps prior to treatment application to 0 at 34 DAT, whereas aphid and adult wheat bug numbers in the controls averaged $2.5( \pm 0.7)$ and $1.5( \pm 0.6) / 10$ sweeps during the experiment, respectively. Adult potato mirid and wheat bug numbers were not significantly $(\mathrm{P}>0.05)$ reduced in the treated plots compared with the control plots. Aphid numbers, however, were significantly $(\mathrm{P}<0.001)$ reduced at 2, 5, and $9 \mathrm{DAT}$ in the treated plots when compared to the control plots.

Numbers of ACM nymphs reached a peak of 32/10 sweeps 16 DAT in the control plots (Figure 1a) and were significantly $(\mathrm{P}<0.001)$ higher at all sampling dates after spray application compared with numbers in the treated plots. Adult ACM numbers in the control plots increased during the season to reach a peak of 24.5/10 sweeps 34 DAT (Figure 1b). The treated plots had significantly $(\mathrm{P}<0.001)$ lower numbers of ACM adults compared with the control plots for all sampling dates after spray application.

The most abundant natural enemies found in the lucerne crop were Pacific damsel bugs (Nabis kinbergii (Reuter)) and harvestman (Phalangium opilio L.). Numbers of Pacific damsel bug adults increased in the control plots from $0.3( \pm 0.2)$ to $2( \pm 0.7) /$ 10 sweeps prior to treatment application and 34 DAT, respectively, while the numbers of nymphs remained around $0.5( \pm 0.4) / 10$ sweeps for the duration of the experiment. There were significantly $(\mathrm{P}<0.01)$ fewer adult Pacific damsel bugs in the treated plots 5, 9 and 16 DAT compared with the control plots, while the numbers of nymphs were similar in both plots during the experiment. Harvestman numbers ranged from $0 / 10$ sweeps 5 DAT to $4( \pm 1) / 10$ sweeps 34 DAT and, overall, averaged $1.8( \pm 0.7) / 10$ sweeps in the control plots. Harvestman numbers were significantly $(\mathrm{P}<0.01)$ lower in treated plots 2, 9 and 16 DAT, compared with the control plots. 

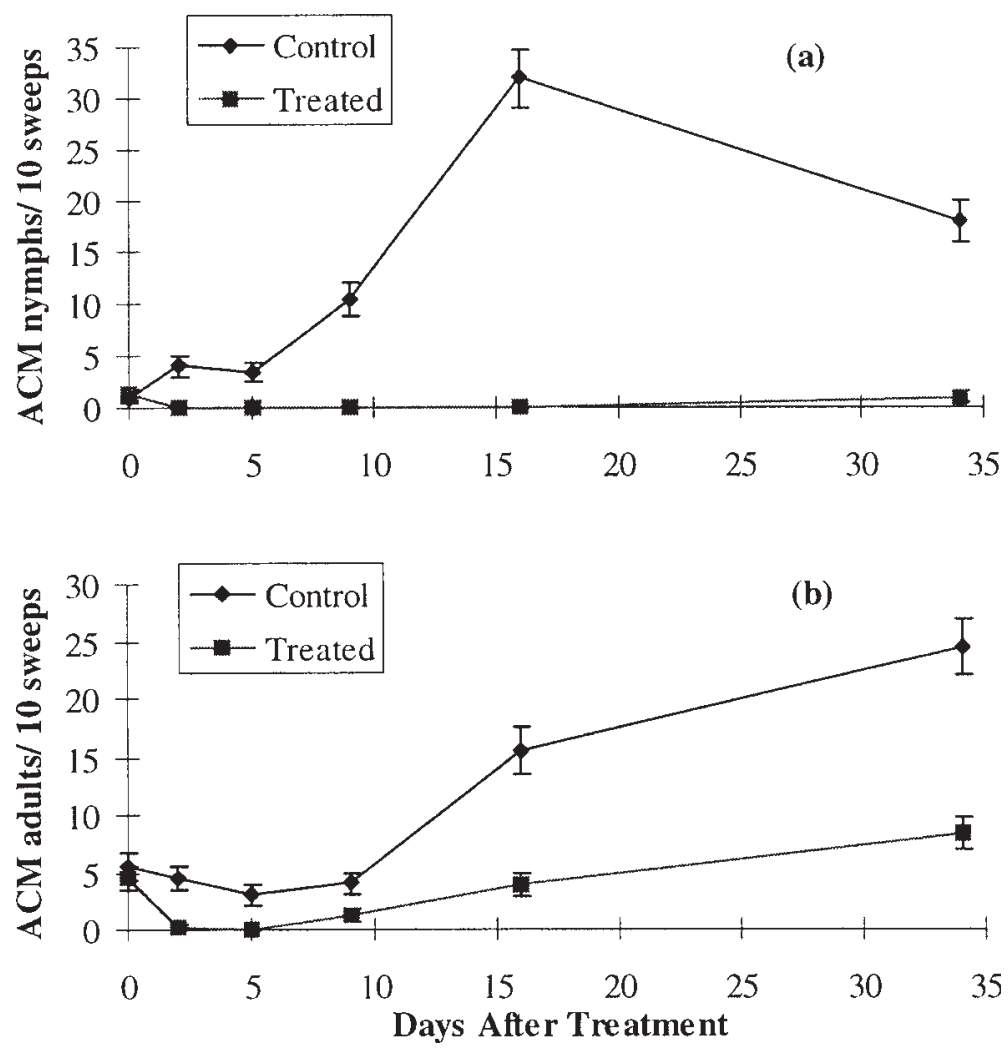

FIGURE 1: Numbers of Australian crop mirid (a) nymphs and (b) adults $( \pm$ SEM) collected by sweep net two days before ( 0 DAT) and after application of lambda-cyhalothrin in a lucerne seed crop, Canterbury.

\section{Red clover}

Of the hemipteran pests collected from the control plots ACM nymphs and adults, aphids, and adult wheat bugs were consistently recorded in numbers $>1 / 10$ sweeps. Adult wheat bug numbers were not significantly $(\mathrm{P}>0.05)$ reduced in the treated plots compared with the control plots and averaged $( \pm$ SE) $4( \pm 1) / 10$ sweeps in the control plots during the experiment.

Numbers of Australian crop mirid nymphs increased over time and reached a peak of 13.8 $\pm 1.9 / 10$ sweeps in the control plots 34 DAT (Figure 2a). Their numbers were significantly $(\mathrm{P}<0.05)$ lower in the treated plots for all sampling dates after application. Adult ACM numbers were high $(9.5 \pm 1.5 / 10$ sweeps $)$ prior to spray application and decreased to $3( \pm 0.9)$ before recovering to $9.8( \pm 1.6) / 10$ sweeps 34 DAT in the control plots (Figure 2b). There were significantly $(\mathrm{P}<0.001)$ fewer ACM adults collected from the treated plots at 2, 5 and 13 DAT compared with the control plots.

Aphid numbers also increased over time to reach a peak of approximately 400 $( \pm 10) / 10$ sweeps 34 DAT in the control plots (Figure 2c). There were significantly $(\mathrm{P}<0.001)$ lower numbers of aphids collected from the treated plots at 2, 5, 13 and 16 DAT compared with the control plots. Closer observation revealed that the aphids sampled in the sweep net were not found on the red clover plants but on sowthistle 

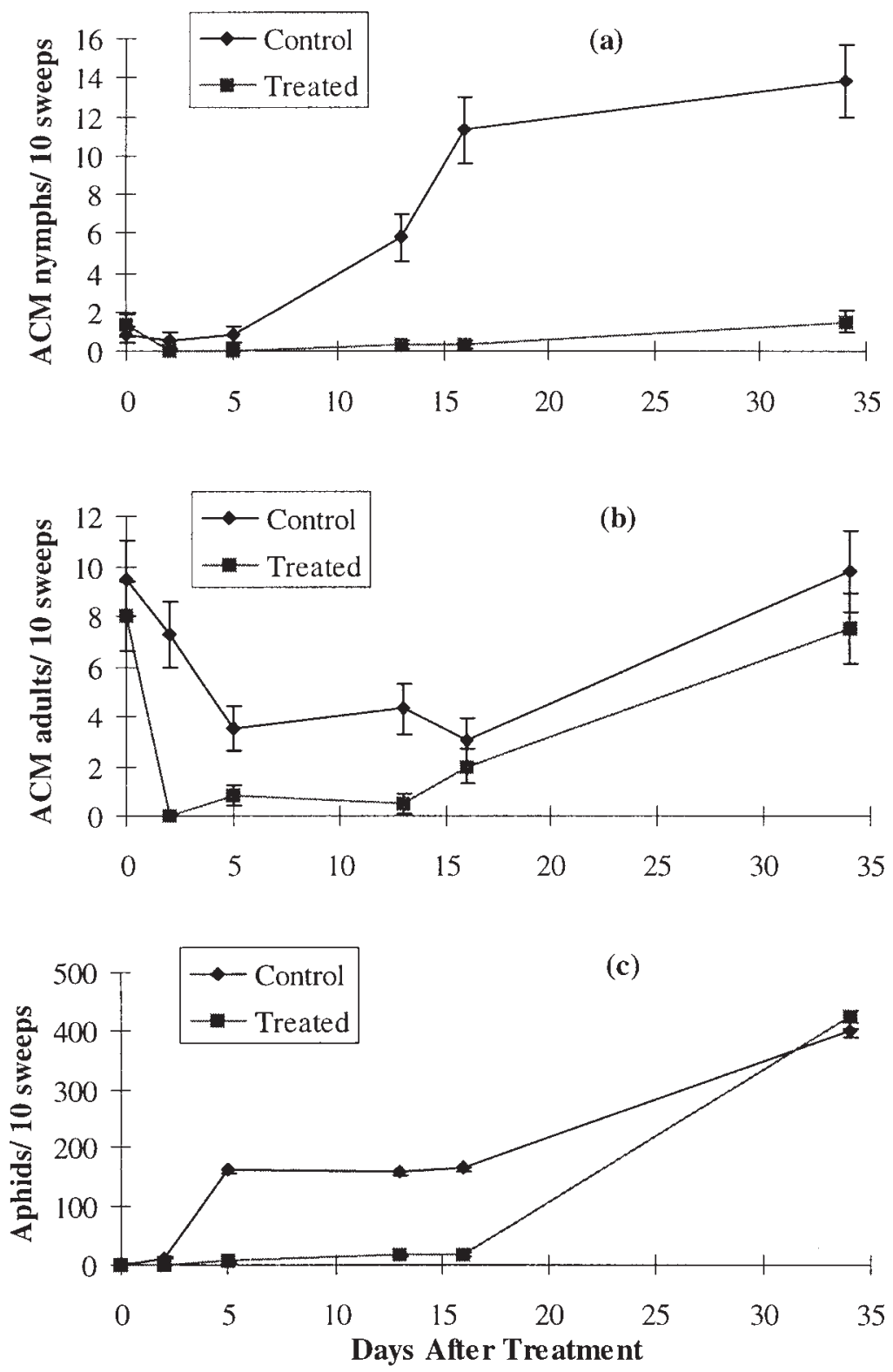

FIGURE 2: Numbers of Australian crop mirid (a) nymphs, (b) adults and (c) aphids $( \pm$ SEM) collected by sweep net two days before $(0$ DAT) and after application of lambda-cyhalothrin in a red clover seed crop, Canterbury. 
(Sonchus spp.) weeds that were numerous throughout the crop. The predominant aphid species collected was therefore likely to be sowthistle aphid (Hyperomyzus lactucae (L.)), although no formal identification was made.

The most abundant natural enemies collected during the red clover experiment were adult and nymphal Pacific damsel bugs and harvestman. Numbers of Pacific damsel bug adults and nymphs reached an average $1.7( \pm 0.6)$ and $1.3( \pm 0.6) / 10$ sweeps, respectively, while harvestman averaged $1.7( \pm 0.7) / 10$ sweeps in the control plots throughout the experiment. Harvestman and Pacific damsel bug adult numbers were not significantly $(\mathrm{P}>0.05)$ different between the treatments during the experiment, whereas Pacific damsel bug nymphs were significantly $(\mathrm{P}<0.05)$ lower at 13,16 and 34 DAT in the treated compared with control plots.

\section{Seed yields}

There were no significant $(\mathrm{P}>0.05)$ differences in seed yields between the control and treated plots. Seed yields in the lucerne plots ranged from 396 to $495 \mathrm{~kg} / \mathrm{ha}$ $\left(\mathrm{LSD}_{0.05} 250\right)$, and from 408 to $460 \mathrm{~kg} / \mathrm{ha}\left(\mathrm{LSD}_{0.05} 87\right)$ in the red clover plots for the control and lambda-cyhalothrin treatments, respectively.

\section{DISCUSSION}

Lambda-cyhalothrin applied at $10 \mathrm{~g} /$ ha significantly reduced the numbers of ACM nymphs in both lucerne and red clover seed crops. Economic thresholds for lucerne seed crops were devised by Wightman and MacFarlane (1981) who applied insecticides before flowering and during flowering if 'bug' counts reached 5/20 sweeps. They also recommended applications if brown shield bug exceeded 5-10 or if ACM numbers reached 10-20/ 20 sweeps after flowering. Of the insecticides recommended by Wightman and MacFarlane (1981), only endosulfan is currently available, but is toxic to honeybees and cannot be applied during flowering. However, there is a lack of experimental information linking the number and phenology of ACM with lucerne plant phenology and seed loss. Pearson (1991) found that one ACM per white clover plant caused a 50\% reduction in inflorescences in field cages. With such a dramatic effect on white clover, it is reasonable to assume that large numbers of ACM in lucerne seed crops could cause drastic seed yield losses as shown by MacFarlane et al. (1981).

Aphids and ACM were the most abundant hemipteran pests collected in the red clover crop. The former, however, were associated with sowthistle. Lambda-cyhalothrin significantly reduced ACM and aphid numbers for varying periods in the red clover seed crop, but had the greatest effect on ACM nymphs and the least on adults. Similar results between the two developmental stages were found by Schroeder et al. (1996) for potato mirid in white clover field experiments. Although no similar studies on insecticide control in red clover crops have been carried out locally, the seasonal growth patterns of red clover and lucerne are similar and they have a similar arthropod fauna. Further study is required to determine the impact of these insect pests in red clover.

Harvestman and Pacific damsel bug numbers showed variable responses to lambda-cyhalothrin application that indicated some toxic effect of lambda-cyhalothrin, but there may also have been some emigration to higher densities of prey in the absence of prey in the treated plots. Serological work conducted by Leathwick and Winterbourn (1984) found that $70 \%$ of the most abundant predators (including harvestman and Pacific damsel bug) found in a lucerne crop gave positive precipitin reactions to Acyrthosiphon spp. antiserum. While it appears that aphids constitute a large proportion of the natural predator's diet, there is no evidence of their predation upon other hemipteran pests. The impact of predators on hemipteran pest populations in lucerne and red clover seed crops is also unknown and requires further study.

Lambda-cyhalothrin has a repellancy and/or antifeedant effect on insects (Blair 1991). The long-term residual effect (up to 34 DAT for ACM) of lambda-cyhalothrin makes it a versatile insecticide that can either be applied as a curative or preventative control for ACM. Future studies in lucerne and red clover crops should concentrate on application timing of lambda-cyhalothrin based on insect pest and plant phenologies to take advantage of the residual effects of this insecticide. 


\section{ACKNOWLEDGEMENTS}

Thanks to Crop Care Holdings for funding this work, David Baird (AgResearch, Lincoln) for help with statistical analysis, and the two growers, Murray Stephens (Irwell) and Richard Oldfield (Tai Tapu) for allowing access to their lucerne and red clover seed crops.

\section{REFERENCES}

Blair, B.W., 1991. The concentration of lambdacyhalothrin and its effects on the cutworm Agrotis segetum (Lepidoptera: Noctuidae). Bull. Entomol. Res. 81: 143145.

Donovan, B.J., 1981. Integrated bug control in lucerne seed crops. N.Z. Farmer, Jan. 8: 18-19.

Gough, H.J. and Wilkinson, W., 1984. PP321- effect on honey bees. Brit. Crop Prot. Conf. Pests and Diseases 1: 331-335.

Leathwick, D.M. and Winterbourn, M.J., 1984. Arthropod predation on aphids in a lucerne crop. N.Z. Entomol. 8: 75-80.

MacFarlane, R.P., Wightman, J.A., Griffin, R.P. and Whitford, D.N.J., 1981. Hemiptera and other insects on South Island lucerne and lotus seed crops 1980-81.Proc. N.Z. Weed and Pest Control Conf. 34: 39-42.

Pearson, W.D., 1991. Effect of meadow spittlebug and Australian crop mirid on white clover seed production in small cages. N.Z. J. Agri. Res. 34: 439-444.

Schroeder, N.C. and Clifford, P.T.P., 1995. The incidence of insect pests and their arthropod predators in 24 Canterbury white clover seed crops. Joint Proc. N.Z. Grass. Assoc. and Agron. Soc. N.Z., White Clover Symposium: 29-33.

Schroeder, N.C., Baird, D.B., Upritchard, E.A. and Simeonidis, A., 1996. Lambdacyhalothrin: an insecticide for hemipteran pest control in white clover seed crops. Proc. 49th N.Z. Plant Prot. Conf.: 304-308.

Wightman, J.A. and MacFarlane, R.P., 1981. The integrated control of pests of legume seed crops: 2. Summation and strategy of the 1980-81 season.Proc. 3rdAustralasian Conf. Grass. Invert. Ecol: 377-384. 